\title{
Resistência do S. pneumoniae à penicilina G no Brasil: a ponta do iceberg
}

\author{
Penicillin susceptibility of Streptococcus pneumoniae in Brazil: the tip of the iceberg
}

\author{
Paulo A.M. Camargos*
}

Os freqüentemente envolvidos nas otites, meningites e pneumonias, e é responsável por um terço dos cinco milhões de óbitos anuais por pneumonia nos países em desenvolvimento. Não bastasse o lugar de destaque que ocupa nas estatísticas de morbi-mortalidade, a crescente elevação da prevalência da resistência do S. pneumoniae à penicilina $\mathrm{G}$ e a outros antimicrobianos verificada em todo o mundo nos últimos 20 anos, constitui-se num complicador de inegável importância clínica. Trata-se, pois, de um microorganismo para o qual devemos direcionar especial atenção, seja na pesquisa científica, seja no exercício diário da clínica.

Desde os anos 60 e 70, quando foram publicados os primeiros relatos sobre o surgimento de cepas invasivas resistentes à penicilina $\mathrm{G}$ na Austrália e na África do Sul, a literatura vem acumulando informações referentes a inúmeros outros países. Na atualidade, sabe-se que as taxas de resistência intermediária e plena variam, juntas, de cerca de $2 \%$ na Alemanha ${ }^{1}$ a quase $60 \%$ na Espanha ${ }^{2}$. Nossa pesquisa bibliográfica identificou oito estudos realizados no Brasil, que reuniram cerca de 1.600 cepas, invasivas e colonizadoras, entre as quais a taxa de resistência intermediária e plena saltou de zero ${ }^{3}$, no início dos anos 80, a 20,0\%, em $1998^{4}$. Auspiciosamente, a eles vieram se somar dois novos estudos, conduzidos nos municípios de São Paulo ${ }^{5}$ e Fortaleza ${ }^{6}$, este último publicado neste fascículo. A prevalência de colonização por $S$. pneumoniae entre crianças cearenses $(55,0 \%)$ foi uma e meia vez superior àquela verificada entre as paulistas $(34,8 \%)$, mas quanto à taxa de resistência à penicilina $\mathrm{G}$, esta foi três vezes maior em Fortaleza (49,0\%) que em São Paulo (15,6\%). No entanto, surpreendentemente, a taxa de resistência à penicilina observada em Fortaleza $(49,0 \%)$ foi três vezes superior à paulista $(15,6 \%)$. Como, então, interpretar estes resultados?

\footnotetext{
* Professor Adjunto Doutor, Departamento de Pediatria da Faculdade de Medicina e Chefe da Unidade de Pneumologia Pediátrica do Hospital das Clínicas, Universidade Federal de Minas Gerais.
}

Muito embora este conjunto de dez investigações encerre diferenças metodológicas, especialmente quanto à representatividade amostral, com evidentes repercussões na validade externa dos resultados, os números são por demais eloqüentes e, antes de tudo, revelam que estamos inegavelmente inseridos na era do pneumococo resistente à penicilina. As duas estratégias por eles adotadas, seja a caracterização de sorotipos colonizadores, seja dos invasivos, são válidas, necessárias e complementares.

São vários os aspectos metodológicos a considerar. Como corretamente pontuam Rey e colaboradores ${ }^{6}$, os estudos de colonização nasofaríngea oferecem-nos o perfil das cepas que circulam numa dada comunidade, e estas, não necessariamente, serão causadoras diretas das doenças invasivas. A recíproca também é verdadeira, e é por esta razão que, recorrendo novamente a estes autores, o citado trabalho tem limitações para a extrapolação dos seus resultados, por não ter incluído no seu desenho, isolados obtidos de sangue e derrame pleural, componente metodológico que ensejaria ilustrativas comparações. Pouco se conhece sobre a dinâmica da colonização nasofaríngea pelo $S$. pneumoniae e o significado do estado de portador e, ainda que ela seja detectada já nas primeiras semanas de vida e perdure durante a infância, estima-se que apenas $1 \%$ das crianças colonizadas desenvolverá doença invasiva ${ }^{7}$. Isso porque o caráter invasivo de um determinado sorotipo não depende de sua resistência à penicilina, mas da sua virulência e do estado imunológico do hospedeiro.

A taxa de resistência à penicilina $\mathrm{G}$ e a distribuição dos sorotipos que se obtém nos estudos com portadores, vale dizer, sorotipos colonizadores, nem sempre se equivalem àquelas verificadas nos estudos que incluíram apenas cepas invasivas. É provável que, se no mesmo período de tempo em que se realizou o estudo de Rey e colaboradores ${ }^{6}$, fossem analisadas concomitantemente uma população de pacientes com doença pneumocócica invasiva, a proporção de resistência não atingiria os $49,0 \%$ por eles verificado, pois, na América Latina percentual próximo (46,9\%) tem sido repetidamente encontrado para cepas invasivas apenas no México, país que detém o maior índice de resistência no 
subcontinente ${ }^{4}$. Quanto à situação brasileira, estudo multicêntrico latino-americano de grande envergadura que logrou obter 1.203 isolados invasivos provenientes de várias cidades brasileiras, revelou que a taxa média de resistência - plena e intermediária - foi de $22,3 \%$ no período 1993 $1999^{4}$. Aponta para direção semelhante a taxa de resistência verificada em dissertação de Mestrado orientada pelo autor deste Editorial, onde foi estudado o perfil de susceptibilidade de 280 cepas invasivas de $S$. pneumoniae, isoladas de pacientes residentes na Capital e interior do estado de Minas Gerais: entre 1997 e 2000, encontrou-se resistência menor $(11,4 \%)$ que a média nacional, mas com tendência de aumento da resistência à penicilina $\mathrm{G}$ estatisticamente significativa no período ${ }^{8}$.

Estas discrepâncias em nada reduzem a relevância dos estudos sobre prevalência de colonização e resistência. Entretanto, ambos contêm um destacado enfoque laboratorial, e é por este motivo que se espera dos futuros estudos sobre este empolgante assunto, a indispensável inclusão do componente clínico, ingrediente que permitirá então a análise de associações geradoras, estas sim, de conhecimentos que balizarão as condutas clínicas, terapêuticas por um lado e até mesmo profiláticas, pois nortearão a composição de vacinas antipneumocócicas. A necessidade de estudos clínico-laboratoriais fica evidenciada, por exemplo, numa instigante constatação: apesar das taxas crescentes de resistência à penicilina $\mathrm{G}$ nos Estados $\operatorname{Unidos}^{9}$ (que podem atingir $40 \%$ na atualidade), houve redução de $84 \%$ nos casos de doença pneumocócica em crianças menores de cinco anos com drepanocitose, submetidas à profilaxia com esta mesma droga $a^{10}$.

Devido à extensão territorial, às heterogêneas densidades populacionais regionais e ainda ao número de habitantes no Brasil, é essencial a utilização e divulgação da informação disponível (na rede de laboratórios de saúde pública, por exemplo) e a implantação de um sistema de vigilância epidemiológica contínuo e específico que nos habilite a enfrentar problema de tal magnitude epidemiológica. Hemoculturas e testes de sensibilidade acessíveis (como o E-teste) deveriam ser incorporados na rotina do atendimento, não apenas das meningites, mas também das pneumonias. Assim, estaremos gerando informações cruciais tanto para a prescrição de regimes terapêuticos adequados, quanto para a formulação de vacinas que venham refletir o perfil dos sorotipos circulantes. A produção científica nacional sobre o assunto é ainda tímida, o que nos leva a conhecer o problema de forma parcial e pulverizada, analogamente ao iceberg, onde a parte imersa é cerca de sete vezes mais alta que a emersa. Preparemo-nos com antecedência - e aqui reside importância do artigo de Rey e colaboradores ${ }^{6}$ - para o cenário mais grave, que seria conviver, no futuro, com elevadas taxas de resistência do $S$. pneumoniae à penicilina $\mathrm{Ge}$ a outros antibióticos, condição que requererá antimicrobianos mais dispendiosos, num país que destina parcos recursos para o setor da saúde.

\section{Referências bibliográficas}

1. Reinert RR, Schlaeger JJ, Mechery V, Lütticken R. Serotype distribution and antibiotic susceptibility of Streptococcus pneumoniae isolates causing systemic infections among children in Germany, 1992 to 1996. Pediatr Infect Dis J 1997;16:244-45.

2. Ramos JT, Saavedra J, Ruiz-Contreras J, Bravo J, Sanz F, Noriega AR. Invasive antibiotic-resistant Streptococcus pneumoniae in children in Madrid. Pediatr Infect Dis J 1998;17:252-55.

3. Teixeira LM. Serotypes and antimicrobial susceptibility of Streptococcus pneumoniae isolated in Rio de Janeiro, Brazil. Rev Microbiol 1988;19:93-99.

4. Di Fabio JL, Castañeda E, Agudelo CI, de la Hoz F, Hortal M, Camou T, et al. Evolution of Streptococcus pneumoniae serotypes and penicillin susceptibility in Latin America, SirevaVigía Group, 1993 to 1999. Pediatr Infect Dis J 2001;20:959-67.

5. Ferreira LLM, Carvalho ES, Berezin EN, Brandileone MC. Colonização e resistência antimicrobiana de S. pneumoniae em rinofaringite aguda. J Pediatr (Rio J) 2001;77:227-34.

6. Rey LC, Wolf B, Moreira JLB, Verhoef J, Farhat CK. S. pneumoniae isolados da nasofaringe de crianças sadias e com pneumonia: taxa de colonização e suscetibilidade aos antimicrobianos. J Pediatr (Rio J) 2002;78:105-12.

7. Greenwood B. The epidemiology of pneumococcal infection in children in developing world. Philos Trans R Soc London B Biol Sci 1999;354:777-85.

8. Bedran MBM. Espectro de sensibilidade do Streptococcus pneumoniae aos antimicrobianos em dois laboratórios de referência [dissertação]. Belo Horizonte: Universidade Federal de Minas Gerais; 2001.p.71.

9. Doern GV, Pflaller MA, Kugler K, Freeman J, Jones RN. Prevalence of antimicrobial resistance among respiratory tract isolates of Streptococcus pneumoniae in North America 1997. Results from the Sentry Antimicrobial Surveillance Program. Clin Infect Dis 1998;27:764-70.

10. Overturf GD. American Academy of Pediatrics. Committee on Infectious Diseases. Technical report: prevention of pneumococcal infections, including the use of pneumococcal conjugate and polysaccharide vaccines and antibiotic prophylaxis. Pediatrics 2000;106:367-76. 